\title{
ACUERDOS CARENTES DE UNA TEORÍA COMPLETA EN DERECHO CONSTITUCIONAL*
}

\author{
CASS R. SUNSTEIN
}

How can the members of a society work together with mutual respect while having deep disagreements between themselves about what is correct and what is good? To think about this question is to think about those factors that make social stability possible, a subject that cannot be ignored by judges and constitutionalists. In this article, the American author offers an answer, explaining how agreements can be reached and decisions made without a complete and robust theory supporting them. His answer also discusses the virtues and limits of this path to social consensus.

En muchos países, los ciudadanos deben enfrentar conflictos y desacuerdos sobre los asuntos más fundamentales. La existencia de valores diversos parece atentar contra la posibilidad real de un orden constitucional. La gente está en desacuerdo con respecto a los derechos, a la vida buena, a la igualdad, a la libertad y a la naturaleza o existencia de Dios. En estas circunstancias, ¿cómo pueden ser factibles las decisiones constitucionales? El problema podría tornarse especialmente serio en sociedades democráticas, que aspiran a autogobernarse. En este ensayo trato dos temas — construcción de la Constitución e interpretación constitucional - en un esfuerzo por lograr algún progreso sobre esa cuestión.'

\footnotetext{
"Ésta es la traducción del artículo anterior. Entre varias formas posibles de traducir la expresión incompletely theorized agreements propuestas a Cass Sunstein, eligió ésta.

${ }^{1}$ He tratado estos aspectos en otros lugares: véase Cass R. Sunstein, One Case At A Time Cambridge: Harvard University Press, 1999; Legal Reasoning and Political Conflict, New York: Oxford University Press 1996.
} 
Mi sugerencia básica es que, con frecuencia, la gente se pone de acuerdo sobre prácticas constitucionales, y hasta sobre derechos constitucionales, cuando no puede ponerse de acuerdo sobre teorías constitucionales. En otras palabras, ordenamientos constitucionales que funcionan bien tratan de resolver problemas a través de acuerdos carentes de una teoría completa. Estos acuerdos incluyen a veces abstracciones aceptadas como tales, en medio de desacuerdos severos sobre casos particulares. Así, quienes están en desacuerdo con la incitación a la violencia y odian su discurso aceptan un principio general de libre expresión, y quienes están en contra de las relaciones homosexuales pueden aceptar un principio abstracto contra la discriminación. Éste es un fenómeno importante en el derecho constitucional y en política; hace posible la construcción de la Constitución. Pero acuerdos carentes de una teoría completa a veces incluyen resultados concretos en vez de abstracciones. En casos difíciles, la gente puede ponerse de acuerdo en que cierta práctica es constitucional o no lo es, aun cuando las teorías que subyacen a sus juicios divergen abruptamente.

Este último fenómeno sugiere que cuando las personas no se ponen de acuerdo o tienen dudas sobre una cuestión abstracta — ila igualdad es más importante que la libertad?, iexiste el libre albedrío?, ies correcto el utilitarismo? - con frecuencia pueden avanzar al desplazarse hacia un nivel de mayor particularidad. Buscan un descenso conceptual. Este fenómeno tiene un rasgo especialmente notable: consigue que se haga silencio sobre ciertas cuestiones básicas, como mecanismo para generar convergencia a pesar del desacuerdo, la incertidumbre, las limitaciones de tiempo y de capacidad, y la heterogeneidad. Los acuerdos carentes de teoría completa son una fuente importante del éxito del constitucionalismo y de la estabilidad social; también proveen de una forma de expresar respeto mutuo entre las personas.

Consideremos algunos ejemplos. La gente puede creer que es importante proteger la libertad religiosa y al mismo tiempo tener teorías del todo diversas sobre por qué esto es así. Algunas personas pueden hacer énfasis en que lo ven necesario para la paz social; otras pueden pensar que la libertad religiosa refleja un principio de igualdad y un reconocimiento de la dignidad humana; otras pueden invocar consideraciones utilitaristas; otras hasta pueden pensar que la libertad religiosa es un mandato teológico en sí mismo. De manera similar, la gente puede invocar muchos fundamentos diferentes sobre su creencia compartida de que la Constitución debería asegurar una judicatura independiente. Algunos pueden pensar que la independencia judicial ayuda a la protección contra la tiranía; otros pueden pensar que hace más democrático al gobierno; y otros hasta pueden pensar que conduce a mayores niveles de eficiencia. 
El acuerdo sobre las particularidades carece de teoría completa, en el sentido de que los participantes más pertinentes tienen clara la práctica o el resultado, sin estar de acuerdo en la más general de las teorías sustentadoras. Con frecuencia la gente puede estar de acuerdo en que una regla - proteger a quienes disientan en política, permitir que los trabajadores practiquen su religión - tiene sentido, sin estar completamente de acuerdo con respecto a los fundamentos de su creencia. La gente puede aceptar una decisión - afirmar el derecho al matrimonio, proteger el arte sexualmente explícito- sin entender o sin converger con respecto a un fundamento definitivo para tal aceptación. Con frecuencia, las personas pueden ponerse de acuerdo no sólo en el resultado, sino también en una explicación que ofrezca principios de nivel bajo o medio en su favor. Pero se deja sin explicación lo que en última instancia, en términos de una teoría completa de lo correcto o de lo bueno, responde por el resultado.

Hay un caso extremo de carencia de teoría completa, que se presenta cuando es especialmente intenso el desacuerdo: el caso de la plena particularidad. Este fenómeno se presenta cuando las personas se ponen de acuerdo sobre una decisión sin ponerse de acuerdo en algún tipo de explicación que la sustente. Cualquier explicación — cualquier razón—es por definición más abstracta que el resultado que sostiene. Algunas veces la gente no ofrece razones porque no conoce qué son esas razones, o porque no se puede poner de acuerdo sobre razones, o porque teme que las razones que tiene pueden resultar inadecuadas si se reflexiona al respecto, lo que puede conducir a su mal uso en el futuro. Este es un fenómeno importante en el derecho anglo-americano. Normalmente los jurados no dan razones para sus conclusiones y los negociadores algunas veces concluyen que algo debe suceder sin decir por qué debe suceder. Aquí no voy a hacer énfasis en este caso límite, y en su lugar me enfocaré en decisiones que van acompañadas de principios de nivel bajo o medio.

Mi énfasis sobre acuerdos carentes de teoría completa pretende ser en parte descriptivo. Estos acuerdos son un fenómeno muy difundido en la construcción de la Constitución y en derecho constitucional. Tales acuerdos son cruciales cuando se trata de lograr decisiones efectivas en medio de intenso desacuerdo. Pero también busco realzar algunos aspectos sobre constitucionalismo en medio del pluralismo. En pocas palabras, hay virtudes especiales para evitar conflictos teóricos en gran escala. Los acuerdos carentes de teoría completa pueden operar como fundamentos tanto para las reglas como para analogías, y tales acuerdos encajan especialmente bien dentro de los límites de diversas instituciones, incluyendo los legisladores y las cortes. Los acuerdos carentes de teoría completa también encuentran su lugar en el sector privado. Pueden 
encontrarse en cuestiones acerca de facultades universitarias, en el lugar de trabajo y hasta en las familias.

\section{Cómo converge la gente}

Parece claro que, por fuera del derecho, la gente puede ponerse de acuerdo en una decisión correcta aunque carezca de una teoría que respalde sus juicios. Usted puede saber que cuando se suelta un objeto éste cae, que la picadura de una abeja duele, que el aire caliente se eleva, y que la nieve se derrite, sin saber exactamente por qué son ciertos estos hechos. Lo mismo ocurre en lo moral, tanto en lo general como cuando se relaciona con el derecho constitucional. Usted puede saber que la esclavitud es mala, que el gobierno no debe acabar con las protestas políticas, que cada persona debe tener sólo un voto, que está mal si el gobierno expropia su tierra a no ser que pague por ella, sin tener un exacto o completo conocimiento del porqué de estas cosas. Los juicios morales pueden ser correctos o verdaderos aunque sean alcanzados por personas que carecen de una explicación completa sobre ellos (si bien los que reflexionan sobre lo moral podrían obrar mejor si trataran de ofrecer tal explicación, punto sobre el cual volveré). Un juez puede saber que el gobierno que castiga un comportamiento religioso actúa ilegalmente, sin comprender plenamente por qué este principio se ha convertido en ley. Podemos señalar entonces un aspecto epistemológico: la gente puede saber que X es verdadero sin saber plenamente por qué X es verdadero.

También hay un aspecto político. Algunas veces la gente puede estar de acuerdo respecto a decisiones individuales aun sin estar de acuerdo en la teoría general. En el derecho constitucional americano, por ejemplo, diversos jueces pueden estar de acuerdo en que Roe v. Wade, que protege el derecho a elegir el aborto, no debería ser modificado, aunque difieran radicalmente las razones que llevan a cada uno a esa conclusión. Algunos piensan que la Corte debería respetar sus propios precedentes; otros piensan que Roe fue una decisión correcta como medio para proteger la igualdad de las mujeres; otros piensan que el caso fue una decisión correcta como medio para proteger la privacidad; otros piensan que la decisión refleja un juicio adecuado sobre el papel social de la religión; y otros piensan que las restricciones del aborto son una protección improbable para los fetos en el mundo, y por ello la decisión

\footnotetext{
${ }^{2} 410$ U.S. 113 (1973). N. de Precedente: se refiere a la decisión de la Corte Suprema (1973) que, en el caso Roe v. Wade, declaró que las mujeres tienen el derecho protegido constitucionalmente al aborto en las primera fases de la gestación. Sobre la oposición a revocar Roe, ver Planned Parenthood v. Casey, 112 S Ct 2791 (1992).
} 
es buena por razones pragmáticas o consecuencialistas. Podemos encontrar acuerdos políticos carentes de una teoría completa sobre resultados particulares en muchas áreas del derecho y la política — en ambos lados de las controversias sobre la discriminación, en ambos lados de las disputas sobre la justicia criminal, en ambos lados de las disputas sobre impuestos, en ambos lados de las disputas sobre la seguridad nacional. En el partido republicano y entre jueces republicanos designados hay acuerdos carentes de teoría completa; y hay acuerdos similares en el partido demócrata y entre jueces designados por demócratas. Algunos de los acuerdos más interesantes de ese tipo se pueden encontrar no dentro de un partido sino entre partidos.

\section{Reglas y analogías}

Las reglas y las analogías son los dos métodos más importantes para resolver disputas constitucionales sin obtener un acuerdo sobre principios fundamentales. Ambos dispositivos — claves en el derecho público de muchas naciones - buscan promover una meta importante de una sociedad heterogénea: hacer posible la obtención de acuerdo donde el acuerdo sea necesario y hacer innecesaria la obtención de acuerdo donde sea imposible un acuerdo.

Las personas pueden con frecuencia estar de acuerdo sobre lo que son las reglas constitucionales aun cuando sólo estén de acuerdo en muy poco más. Y frente al desacuerdo persistente o a la incertidumbre sobre lo que requieren la justicia y la moral, las personas pueden razonar sobre casos constitucionales particulares haciendo referencia a las analogías. Las personas apuntan hacia los casos en los cuales son firmes las decisiones legales. Proceden a partir de dichas decisiones firmes hacia las más difíciles. De hecho, así es como tiende a pensar el común de la gente.

En este respecto podemos considerar la discusión del juez de la Corte Suprema de Justicia Stephen Breyer, sobre uno de los compromisos claves logrados por los siete miembros de la Comisión de Sentencias de los Estados Unidos. ' Como lo describe Breyer, un asunto central fue cómo proceder frente a premisas filosóficas altamente dispares sobre las metas del castigo penal. Algunas personas pidieron a la comisión abordar el castigo con base en "el justo merecido" - un método que calificaría la conducta criminal en términos de severidad-. Pero había distintos puntos de vista entre los diferentes comisionados acerca de cómo calificar los distintos delitos. Según el juez Breyer, en

\footnotetext{
${ }^{3}$ Breyer, The Federal Sentencing Guidelines and the Key Compromises Upon Which They Rest, 17 Hofstra L. Rev. 1, 14-19 (1988).
} 
estas circunstancias se podría presentar una extraña manera de deliberación en la cual los castigos penales se tornarían cada vez más irracionalmente severos, debido a que algunos comisionados insistirían que el crimen en consideración sería peor que otros ya calificados. En todo caso, sería improbable que de los esfuerzos de los siete comisionados se lograra un acuerdo sobre un sistema racional para calificar los delitos en términos de severidad.

Otras personas urgieron a la Comisión para que utilizara un modelo disuasivo. Sin embargo, había serios problemas con este método. No hay una buena evidencia empírica que relacione todas las posibles variaciones del castigo para prevenir el delito. En cualquier caso, era muy improbable que los siete miembros de la comisión estuvieran de acuerdo en que la disuasión suministra el adecuado soporte a los objetivos de la sentencia criminal. Para muchas personas es controversial sugerir que la disuasión es la única o principal meta de la pena. Un método basado en la disuasión no parecería mejor que un método basado en lo justo merecido.

En estas circunstancias, ¿qué ruta tomó la Comisión? En realidad, la Comisión abandonó totalmente las grandes teorías. No adoptó un punto de vista general de los fines adecuados de la sentencia criminal. En vez de eso la Comisión adoptó una regla basada en precedente: "Decidió basar las reglas principalmente sobre la práctica pasada real típica o promedio. Se usaron explicaciones conscientemente articuladas, no basadas en alta teoría, para dar soporte a desviaciones particulares del pasado. La decisión de adoptar este método debe haberse basado en la creencia de que la práctica típica o promedio tenía más sentido que sinsentido - una creencia que se puede apoyar haciendo referencia al teorema del juez Condorcet y a la frecuente "sabiduría de las masas".

El juez Breyer estima este esfuerzo como un medio necesario para lograr acuerdo y racionalidad dentro de un cuerpo diverso, conformado por varios miembros, encargado de evitar variaciones injustificadas en las sentencias. De allí su más colorida presentación oral: "iPor qué no se sentó la Comisión y de veras se dedicó, y se puso a razonar sobre la cosa en vez de basarse en la historia? La respuesta corta a esta pregunta es: no podíamos. No podíamos porque existen argumentos tan buenos por todos lados, apuntando en direcciones opuestas [...] Trate de enumerar en orden de posición por castigo merecido

${ }^{4}$ Para un manejo popular ver James Surowiecki, The Wisdom of Crowds (2005); un análisis más técnico, con referencia al Teorema del Jurado Condorcet, puede hallarse en Cass R. Sunstein, Infotopia: How Many Minds Produce Knowledge (New York: Oxford University Press, 2006). 
todos los delitos que hay... Recoja después los resultados entre sus amigos y observe si concuerdan. Le diré que no". 5

El ejemplo sugiere un punto más general. A través de analogías y reglas es con frecuencia posible que los participantes en derecho constitucional converjan sobre principios abstractos y resultados particulares sin resolver cuestiones de gran escala sobre derecho o sobre lo bueno. De hecho, la Declaración Universal de los Derechos Humanos se produjo mediante un proceso parecido al descrito por el juez Breyer, con un rechazo a comprometerse en alta teoría y, en cambio, esforzándose en construir a partir de modos de ver muy difundidos. ${ }^{6}$ La tarea básica se llevó a cabo investigando la mayoría de los comportamientos de naciones, y construyendo una "declaración universal" sobre la base de prácticas compartidas. Un grupo de filósofos que participó en el proyecto "empezó su trabajo enviando un cuestionario a estadistas y académicos alrededor del mundo". En un momento clave, quienes estaban encargados de redactar la declaración produjeron "una lista de cuarenta y ocho ítems que representaban el núcleo común" de una amplia cantidad de documentos y propuestas, que incluía juicios de las naciones y culturas "árabe, británica, canadiense, china, francesa, alemana pre-nazi, italiana, latinoamericana, polaca, ruso soviética y española". ${ }^{8}$ Es famoso lo que dijo Jacques Maritain, un filósofo íntimamente involucrado en la declaración universal: "Sí, estamos de acuerdo sobre los derechos, pero con la condición de que nadie nos pregunte por qué". 9 Por lo tanto, una decisión sobre un conjunto de derechos puede emerger del desacuerdo o de la incertidumbre acerca de los fundamentos de esos derechos.

\section{Rasgos de la analogía}

El pensamiento analógico es constante en el derecho y en la vida diaria. Las personas proceden analógicamente en sus discusiones de asuntos políticos

\footnotetext{
${ }^{5}$ De acuerdo a como se cita en The New Republic, June 6, 1994, p. 12.

${ }^{6}$ Ver Mary Ann Glendon, A World Made Anew (2001).

${ }^{7}$ Id. at 51.

${ }^{8}$ Id. at 57.

${ }^{9}$ Id. at 77 (citando a Maritain); también citado en http://www.catholicculture.org/docs/doc_view. cfm?recnum = 405. [ Nota de Precedente: Los trabajos de filósofos citados más arriba, junto con el texto oficial de la Declaración Universal de Derechos del Hombre, se encuentran en Los derechos del hombre. Estudios y comentarios en torno a la nuevas declaración universal, México, Fondo de Cultura Económica, 1949].
} 
y legales. Usted piensa que el discurso del odio racial no está protegido por la primera enmienda; iquiere decir esto que el gobierno puede silenciar a los extremistas? Una técnica argumentativa familiar es demostrar inconsistencia entre lo que alguien exige acerca del caso $\mathrm{X}$ a la luz de lo que piensa acerca del caso Y. La meta es revelar hipocresía o confusión, o forzar al demandante a que demuestre cómo el compromiso al parecer profundo sobre el caso acerca del cual los disputantes están de acuerdo puede cuadrar con su punto de vista sobre un caso en el que ellos están en desacuerdo.

En el pensamiento analógico tal como lo entiendo aquí, no se despliegan profundas teorías sobre el bien o el derecho. Por otro lado, quienes proceden analógicamente no pueden razonar desde algo particular hacia otro particular sin al menos mencionar algo un poco abstracto. Deben invocar una razón de principio o de política en el sentido de que el caso A se decidió correctamente por una razón, y deben decir que esa razón se aplica o no se aplica en el caso B. Este método de procedimiento se ajusta de manera ideal a un sistema legal que consiste en muchos jueces que disienten sobre principios fundamentales y que deben basarse sobre casos ya decididos como puntos fijos para proceder desde allí. Por la misma razón, quienes no trabajan en derecho, con frecuencia piensan analógicamente en casos difíciles.

Consideremos algunos ejemplos. Sabemos que un empleador no puede despedir a un empleado que se preste para desempeñar sus deberes de jurado; se dice que "se sigue" de aquí que a un empleador le está prohibido despedir a un empleado por rehusarse a cometer perjurio. Sabemos que no se puede restringir un discurso de un miembro del Ku Klux Klan promoviendo el odio racial, a no ser que sea probable que incite y que esté dirigido a incitar a una acción ilegal inminente ${ }^{10}$ se dice que, como consecuencia, el gobierno no puede prohibir marchas de miembros del partido nazi en Skokie, Illinois. Sabemos que no hay derecho constitucional al bienestar, a cuidado médico, o a vivienda; ${ }^{11}$ se dice que de eso se sigue que no hay derecho constitucional a la protección del gobierno contra la violencia familiar por parte del Estado."

\footnotetext{
${ }^{10}$ Ver Brandenburg v. Ohio, 395 U.S. 444 (1969).

${ }^{11}$ Ver Dandridge v. Williams, 397 U.S. 471 (1970).

* Nota de Precedente: El autor se refiere a la Constitución de Estados Unidos que no incorpora en su articulado, ni en su Bill of Rights o Carta de Derechos, los derechos económicos sociales y culturales, como sí ocurre en las constituciones contemporáneas, como la colombiana de 1991. Es importante anotar que la primera Constitución que reconoce los derechos sociales es la mexicana, en 1917.
} 
De una rápida mirada a estos casos podemos formarnos una idea acerca de la forma característica del pensamiento analógico en derecho. Parece que el proceso funciona en cinco pasos simples. (1) Un hecho con forma A -el caso "fuente" - tiene ciertas características; llámense X, Y y Z. (2) Un hecho con forma B -el caso "blanco" (target) - tiene características X, Y y A, o características X, Y, Z y A. (3) En derecho, A es tratado de cierta manera. (4) En el proceso de pensamiento sobre A, B y sus interrelaciones, se crea o descubre algún principio que explica por qué $A$ se trata de tal manera. (5) Por lo que $\mathrm{B}$ tiene en común con $\mathrm{A}$, debe ser tratado de la misma manera. Está bajo el mismo principio.

Algunas personas piensan que el razonamiento analógico es realmente una manera de deducción; pero esto es un error. Está claro que el razonamiento analógico no puede proceder sin primero identificar una idea directa -un principio, un estándar, o una regla- que respalde los resultados en los casos "fuente" y "blanco". Este es el paso crucial (4) antes mencionado. Pero la idea directiva por adelantado, aplicándose al nuevo caso. Por el contrario, el razonamiento analógico ayuda a identificar la idea fundamental y es indispensable para eso; no conocemos cuál es la idea hasta que no hayamos valorado los casos. La analogía o la disimilitud se crea o se descubre a través del proceso de comparación de casos, a medida que las personas disciernen un principio que les da sentido a sus juicios en consideración.

En derecho, el razonamiento analógico opera sin tener en cuenta una teoría profunda o comprehensiva que justifique los resultados particulares que se derivan. Los juicios que subyacen a las convicciones sobre el caso pertinente carecen de una teoría completa. Por supuesto que hay una continuidad desde los principios más particulares y de bajo nivel a los más profundos y más generales. También es cierto que quienes se involucran en un razonamiento analógico tendrían que ser más ambiciosos de lo que desearían para pensar bien sobre los casos difíciles. Sólo les sugiero a los analogistas del derecho que traten de evitar esas aproximaciones que se acercan mucho a lo profundamente teorizado o a lo fundacional. Tenerlo en cuenta hace posible que se llegue a un acuerdo en medio de la heterogeneidad.

En este punto podría preguntarse: ipor qué es tan importante el acuerdo en el constitucionalismo y en todo lo demás? El hecho de que las personas puedan llegar a un acuerdo de este tipo -sobre el valor y el significado de un derecho o sobre la existencia de una analogía sólida- no garantiza un buen resultado. Es posible que la Comisión de Sentencias haya incorporado decisiones que estaban basadas en la ignorancia, la confusión o el prejuicio. Algunas de estas 
cosas se pueden decir sobre las analogías. Personas con cargos de autoridad pueden acordar que una prohibición del matrimonio entre personas de un mismo sexo es constitucionalmente aceptable, porque es análoga a la prohibición del matrimonio entre tíos y sobrinas; pero la analogía puede estar mal concebida, puesto que hay diferencias relevantes entre los dos casos y debido a que las similitudes están lejos de ser decisivas, el que las personas se pongan de acuerdo en que un caso constitucional $A$ es análogo a un caso $B$ no significa que estén bien decididos el caso A o el caso B. Quizás el caso A no se debiera dar por sentado. Tal vez no se debería seleccionar el caso A como fundamento pertinente para el pensamiento analógico; quizás el caso $Z$ sea más pertinente. Quizás el caso B realmente no es como el caso A. Los problemas de analogías y de pensamiento de bajo nivel deberían conducirnos a ser más ambiciosos. Es posible que seamos empujados en la dirección de una teoría general —y hacia pretensiones más amplias y tal vez más polémicas - precisamente porque los pensadores analógicos ofrecen el respaldo de una teoría incompleta e inadecuada con respecto a similitudes relevantes o a relevantes diferencias.

Esto debería ser suficiente para demostrar que son parciales las virtudes de las decisiones por regla o por analogía. Pero es improbable que algún sistema político y de derecho pueda ser justo o eficiente si dispensa con reglas y analogías. De hecho, es probable que ni siquiera sea factible.

\section{Constituciones, casos y acuerdos carentes de teoría completa}

Los acuerdos teóricos carentes de teoría completa juegan un difundido papel en el derecho constitucional y en la sociedad en general. Es muy raro que una persona o un grupo teorice un asunto de manera exhaustiva, es decir, que acepte tanto una teoría general como la serie de pasos que conectan dicha teoría con conclusiones concretas. Por eso es que con frecuencia llegamos a un acuerdo carente de teoría completa sobre un principio general, queriendo decir con esto que las personas que aceptan el principio no necesitan estar de acuerdo sobre lo que implica en casos particulares. Este es el sentido subrayado por el juez de la Corte Suprema de Justicia de Estados Unidos Oliver Wendell Holmes, en su gran aforismo "Los principios generales no deciden los casos particulares". ${ }^{12}$ El acuerdo carece de teoría plena ya que está especificado de manera incompleta. Mucho del trabajo clave debe ser hecho por otros, frecuentemente a través de decisiones casuísticas, especificando la abstracción en el punto de aplicación.

\footnotetext{
${ }^{12}$ Lochner v. New York, 198 U.S. 48, 69 (1908) (Holmes, J., en disentimiento. Nota de Precedente: salvamento de voto a la decisión plena de la Corte Suprema de Justicia).
} 
Considérense los casos de Europa Oriental, Irak y Sur África, donde las disposiciones constitucionales incluyen muchas provisiones abstractas sobre cuya especificación concreta se han presentado fuertes disputas. Tales disposiciones protegen "la libertad de expresión", "la libertad de religión" y "la igualdad bajo la ley", y los ciudadanos están de acuerdo en dichas abstracciones en medio de la disputa acerca de lo que ellas implican realmente. Mucha legislación también se hace posible sólo por este fenómeno. Y cuando se hace difícil o imposible llegar a un acuerdo sobre una Constitución escrita, se debe a que es difícil obtener consenso sobre las abstracciones fundamentales. Considérese el caso de Israel, que carece de Constitución escrita porque sus ciudadanos no han sido capaces de llegar a un acuerdo sobre principios básicos, aunque se expongan a un alto nivel de abstracción.

Los observadores del constitucionalismo democrático pueden hacer énfasis particular en un tipo distinto de fenómeno, de especial interés para el derecho constitucional en las cortes: acuerdos sobre decisiones particulares, pero con respaldo teórico incompleto, acompañados de acuerdos sobre principios restringidos o de nivel bajo que dan cuenta de ellos. No existe un algoritmo con el cual se pueda distinguir entre una teoría de alto nivel y una que opera a un nivel intermedio o bajo. Podríamos considerar —como ejemplos conspicuos de teorías de alto nivel - el kantismo y el utilitarismo, y observar ilustraciones en los muchos esfuerzos (académicos) distinguidos para entender áreas tales como el derecho por daño causado, el derecho contractual, la libertad de expresión, y la ley de igualdad, como sostenidas por la estructura de teorías de alta abstracción sobre lo correcto o lo bueno. En contraste, podríamos pensar los principios de bajo nivel como incluyendo la mayoría del material común de justificación constitucional de bajo nivel o la "doctrina" constitucional —la clase general de principios y justificaciones que tienden a dar las cortes-. No está dicho que estos principios se derivan de alguna de las altas teorías en particular sobre lo correcto o lo bueno; tienen relaciones ambiguas con altas teorías y son compatibles con más de una de ellas.

Con la expresión "principios de bajo nivel" me refiero a algo relativo, no absoluto; y lo mismo hago con los términos "teorías" y "abstracciones" (términos que intercambio). En este orden de ideas, las nociones "bajo nivel", "alto" y "abstracto" se comprenden mejor en términos comparativos, tales como "grande", "viejo" e "inusual". Así el estándar del "peligro claro y presente" para la regulación de la expresión en el derecho americano es una abstracción relativa cuando se la compara con la pretensión de que el gobierno no puede impedir un discurso que aconseje violencia en la Internet, o que los miembros del partido nazi puedan marchar en Skokie, Illinois. Pero la idea del "peligro 
claro y presente" es relativamente particular cuando se la compara con la afirmación de que las naciones deberían adoptar la abstracción constitucional "libertad de expresión". "Libertad de expresión" es una abstracción relativa cuando se la confronta con la afirmación de que son aceptables las leyes sobre finanzas de campañas, pero la misma expresión es menos abstracta que las bases que justifican la libertad de palabra, como por ejemplo, el principio de autonomía personal.

Este fenómeno siempre ocurre en el razonamiento analógico. En el derecho de discriminación, por ejemplo, muchas personas piensan que la discriminación sexual es "como" la discriminación racial, y que debería tratarse de manera similar, aunque carezcan de una teoría general sobre cuándo es inaceptable la discriminación o no puedan ponerse de acuerdo sobre una teoría. Cuando se trata de la libertad de palabra, muchas personas están de acuerdo en que la prohibición de la expresión a un comunista es "como" la prohibición de la expresión a un miembro de un partido político fascista, y que deberían manejarse de modo similar, aunque carezcan de una teoría general o no puedan ponerse de acuerdo sobre una teoría general acerca de los fundamentos del principio de libertad de expresión.

\section{La teorización incompleta y los usos constructivos del silencio}

¿Qué podría decirse a favor de los acuerdos que no cuentan con una teoría completa sobre el contenido de la Constitución, o de los juicios carentes de teoría completa sobre casos constitucionales particulares? Algunas personas consideran muy infortunada la teorización incompleta -desconcertante, o reflejo de algún problema importante, o falta de agallas, o hasta filistea-. Cuando las personas teorizan, elevando el nivel de abstracción, lo hacen para revelar sesgos, o confusión, o inconsistencia. Con seguridad los participantes en política y en derecho constitucional no deberían abandonar este esfuerzo.

Hay una verdad importante en estos pensamientos habituales; no tendría sentido celebrar siempre y en todos los contextos la modestia teórica. A veces los participantes en derecho constitucional y en política tienen suficiente información, y suficiente acuerdo, como para ser enérgicamente activos (very ambitious). A veces tienen que razonar ambiciosamente con el fin de resolver los casos. Pero las decisiones con teoría incompleta son una importante y valiosa parte tanto de la vida privada como de la pública. Ellas hacen posible la construcción de Constituciones y el derecho constitucional; hasta hacen posible la vida social. El silencio -sobre algo que puede resultar falso, obtuso, o excesivamente contencioso- puede ayudar a minimizar el conflicto, puede 
permitir que el presente aprenda del futuro, y ahorrar gran cantidad de tiempo y de costos. Lo que se dice y se resuelve puede ser no más importante que lo que se deja por fuera. Hay cuatro aspectos aquí.

El primero y el más obvio es que los acuerdos con teoría incompleta sobre principios y casos constitucionales pueden ser necesarios para la estabilidad social. Encajan perfectamente en un mundo - especialmente un mundo legal- que contiene desacuerdos sociales sobre asuntos de gran escala. Sería difícil obtener estabilidad si estallaran desacuerdos fundamentales en todos los casos de disputa pública o privada.

Segundo, los acuerdos con teoría incompleta pueden promover dos metas de una democracia constitucional y de un sistema legal liberal: hacer posible a la gente la convivencia y permitir que cada uno muestre a los demás cierta medida de reciprocidad y respeto mutuo. El uso de principios de bajo nivel o de reglas permite a los jueces en cuerpos de muchos miembros, y por lo tanto a los ciudadanos en general, encontrar propósitos compartidos y por ende un modo de vida común, sin producir antagonismo innecesario. Tanto las reglas como los principios de bajo nivel logran que sea innecesario entrar en áreas en las que el desacuerdo es fundamental. Quizás aun más importante, los acuerdos con teoría incompleta permiten a las personas mostrarse entre sí un alto grado de respeto mutuo, de civilidad o de reciprocidad. Con frecuencia, las personas comunes están en desacuerdo con cierto grado de profundidad sobre una cuestión: qué hacer en el Oriente próximo, que hacer con la pornografía, con los matrimonios entre personas del mismo sexo; y algunas veces convienen en no discutir mucho el asunto, como un modo de dejar al arbitrio de cada uno las convicciones fuertes y de mostrar cierta medida de reciprocidad y respeto (si bien no respeten la convicción particular que está en juego). Si la reciprocidad y el mutuo respeto son deseables, se sigue que los funcionarios públicos o los jueces, más aún quizás que la gente común, no deberían desafiar las convicciones más profundas y determinantes de sus conciudadanos, al menos si esas convicciones son razonables y si ellos no tienen necesidad de hacerlo.

Es claro que, en el sistema legal o dentro de otros cuerpos de miembros múltiples, algunas convicciones fundamentales encuentran desafíos adecuados. La Constitución misma considera fuera de sus límites algunas de tales convicciones. Muchas provisiones que incluyen derechos básicos se encargan de esta función. Por supuesto que no siempre es irrespetuoso estar en desacuerdo con alguien sobre un asunto fundamental; por el contrario, tal desacuerdo puede reflejar un profundo respeto. Cuando los compromisos fundamentales se basan 
en errores demostrables de hecho o de lógica, es apropiado refutarlos. También lo es cuando tales compromisos están basados en el rechazo de la dignidad básica de todos los seres humanos, o cuando se hace necesario asumir la tarea de resolver un problema genuino. Pero son muchos los casos que pueden resolverse con teoría incompleta, y éste es el material común que se encuentra en derecho constitucional. Eso es lo que quiero subrayar aquí.

El tercer aspecto es que para los árbitros de controversias sociales los acuerdos de teoría incompleta tienen la función crucial de reducir el costo político de desacuerdos duraderos. Si los participantes en derecho constitucional desestiman las teorías a gran escala, entonces los perdedores en casos particulares pierden menos. Pierden una decisión, pero no el mundo. Pueden ganar en otra ocasión. Su propia teoría no ha sido rechazada o declarada inadmisible. Cuando el conjunto de argumentos que da autoridad a la decisión está desconectado de las teorías abstractas de lo bueno o de lo correcto, los perdedores pueden aceptar obligaciones legales, aunque con renuencia, sin ser forzados a renunciar a sus ideales más amplios.

En cuarto y último lugar, los acuerdos de teoría incompleta son especialmente valiosos cuando una sociedad se orienta hacia una evolución moral y hacia un progreso en el tiempo. Consideremos el área de la igualdad, en la cual ha ocurrido un cambio considerable en el pasado e inevitablemente ocurrirá en el futuro. Un juicio de teoría completa sería incapaz de generar espacios para cambios en hechos o en valores. Si una cultura en realidad hubiera alcanzado el estado final de una teoría, se habría vuelto rígida y calcificada; sabríamos qué pensar sobre cualquier cosa. A no ser que la teoría completa estuviera libre de todo error, sería nociva para la posteridad. Por lo tanto, los acuerdos carentes de teoría completa son claves para debates sobre la igualdad, tanto en derecho como en política, en los que se avivan cuestiones como las de si la discriminación por orientación sexual, edad, incapacidad y otras son análogas a la discriminación por raza. Tales acuerdos poseen la ventaja importante de permitir un amplio grado de apertura a nuevos hechos y perspectivas. En cierto momento podríamos pensar que las relaciones entre personas del mismo sexo son afines al incesto; en otro momento podríamos encontrar muy rara esa analogía. Por supuesto que una decisión con teoría plena tendría muchas virtudes si fuera correcta. Pero en cualquier momento particular, se trata de una posibilidad poco probable para los seres humanos, sin excluir a los jueces de disputas constitucionales, o a aquellos a quienes se ha confiado la tarea de crear provisiones constitucionales. 
Compárese el razonamiento práctico en la vida diaria. En algunos momentos usted puede rehusarse a tomar decisiones que parezcan de carácter fundamental -por ejemplo, si casarse en el próximo año, o si tener dos, tres o cuatro hijos, o si vivir en San Francisco o en Nueva York-. Una razón para rehusarse a esto es saber que puede variar el conocimiento que usted tiene de los hechos y los valores. En verdad, su identidad puede cambiar de maneras importantes y significativas, y por eso no tendría sentido un conjunto de firmes compromisos por adelantado, algo así como una concepción del curso de su vida respaldada por una teoría plena. Los sistemas legales y las naciones no son algo del todo distinto.

\section{¿Avances conceptuales para el derecho constitucional?}

Apropiándose de lo que escribió Henry Sidgwick sobre el método ético, ${ }^{13}$ un crítico podría responder que el derecho constitucional debería utilizar con frecuencia teorías ambiciosas. ${ }^{14}$ Por ejemplo, a menudo hay buenas razones para que los interesados en los derechos constitucionales eleven el nivel de abstracción y recurran en última instancia a una teoría en gran escala. Las decisiones concretas sobre casos particulares pueden resultar inadecuadas en cuestiones de moral o de derecho constitucional. A veces las personas no tienen claras intuiciones sobre cómo deberían ser resueltos los casos. A veces sus intuiciones no son suficientemente reflexivas. Algunas veces, casos semejantes en apariencia provocan reacciones diferentes, y se hace necesario elevar el nivel de ambición teórica para explicar si se justifican esas reacciones, o demostrar que los casos en apariencia similares son en realidad diferentes. Algunas veces las personas simplemente no se ponen de acuerdo. Podemos mediar en el desacuerdo si prestamos atención a principios más amplios. En todo caso, se trata de explicar nuestros cuidadosos juicios sobre casos particulares, para ver si no se trata sólo del producto de accidente o de error. Cuando jueces modestos se pliegan a una opinión carente de teoría plena, deben basarse en una razón o en un principio, justificando una solución más bien que otra. La opinión misma debe referirse a una razón o a un principio; no puede simplemente declarar un vencedor. Quizás esté equivocado el principio de bajo nivel, porque no encaja con otros casos, o porque es indefendible como asunto (legalmente pertinente) de moralidad política.

\footnotetext{
${ }^{13}$ Ver Henry Sidgwick, The Methods of Ethics, 7a ed. (New York Dover Publications, 1966), pp. 96-104.

${ }^{14}$ Ésta es la tendencia en Ronald Dworkin, Law's Empire, (Cambridge: Harvard University Press, 1985). Nota de Precedente: El Imperio del Derecho, en edición castellana de Editorial Gedisa.
} 
En resumen, el acuerdo carente de teoría completa puede no ser algo que deba ser celebrado. Si un juez razona bien, debería tener ante sí una variedad de otros casos, desde $\mathrm{C}$ hasta Z, en los cuales el principio es sometido a prueba frente a otros y se lo refina. Si es al menos un juez distinguido, experimentará con cierto "ascenso conceptual", en el que el pequeño principio más o menos aislado y de bajo nivel termina haciendo parte de una teoría más general. Esto podría ser quizás una tarea paralizante, y quizás nuestro juez necesite intentarlo no con frecuencia. Pero es un modelo apropiado para entender el derecho y una aspiración apropiada para evaluar las decisiones judiciales y políticas. Los jueces que insisten en quedarse en un bajo nivel de ambición teórica son filisteos, y hasta avestruces.

Hay algo de verdad en esta respuesta. Si al menos tuvieran tiempo, los pensadores morales interesados en derechos básicos deberían tratar de lograr consistencia vertical y horizontal, no sólo las pequeñas áreas locales de coherencia que presentan los acuerdos de teoría incompleta. En los procesos democráticos es apropiado y algunas veces indispensable desafiar en términos abstractos las prácticas existentes. Pero a este desafío a los acuerdos de teoría incompleta no debería dársele más importancia de la que tiene, puesto que cualquier interés de evaluación debe considerar las características distintivas de la arena en la que deben realizar su trabajo quienes hacen las Constituciones y los jueces del mundo real.

Como lo he anotado, los acuerdos carentes de teoría completa tienen muchas virtudes, entre ellas la promoción de la estabilidad, la reducción de los costos del desacuerdo y la demostración de humildad y respeto mutuo. Todo esto puede ser crítico en la construcción exitosa de la Constitución en una sociedad pluralista. Estos aspectos tienen que ver también con disputas constitucionales. En una democracia constitucional que esté funcionando bien, los jueces son especialmente renuentes a invocar abstracciones filosóficas como base para invalidar los resultados de procesos electorales. Son renuentes porque saben que pueden entender a medias los argumentos filosóficos pertinentes y porque su objetivo es mostrar respeto a los diversos ciudadanos en su nación.

Hay muchas preguntas acechando: ¿Cómo sabemos si los juicios morales o políticos son correctos? ¿Cómo se comportan exactamente las apreciaciones morales y políticas en el contenido de la ley? ¿Cuál es la relación entre juicios provisionales o cuidadosos sobre particulares y los juicios correspondientes sobre abstracciones? A veces las personas interesadas en derecho constitucional escriben como si los juicios teóricos abstractos, o las teorías abstractas, 
tuvieran cierto tipo de realidad y de dureza de las cuales carecerían los juicios particulares, o como si las teorías abstractas suministraran las respuestas a las preguntas de un examen que los juicios particulares, débiles como son, pudieran aprobar o perder. De acuerdo con este punto de vista, las teorías son reflectores que iluminan los juicios particulares y hacen ver lo que realmente son. Pero podemos pensar, en cambio, que no hay magia especial en las teorías o abstracciones, y que las teorías sólo son medios (construidos por humanos) con los cuales las personas dan sentido a los juicios que constituyen sus mundos ético, legal y político. Lo abstracto no merece prioridad sobre lo particular, y ninguno de los dos debe ser tratado como fundamental. Una teoría abstracta (pobre o cruda) puede simplemente representar una manera confusa de tratar de dar sentido a los juicios que tenemos sobre casos constitucionales particulares, juicios que pueden ser mejores que la teoría.

\section{Los acuerdos de teoría incompleta y el desacuerdo}

Los acuerdos que carecen de teoría completa tienen muchas virtudes; pero sus virtudes son parciales. La estabilidad, por ejemplo, es un resultado de tales acuerdos, y por lo común la estabilidad es deseable; pero un sistema constitucional que es estable e injusto debería probablemente hacerse menos estable. Consideremos dos calificaciones de lo que hasta ahora se ha mencionado. De ninguna manera se pueden decidir algunas cosas sin introducir una buena cantidad de algo que haga las veces de teoría. Algunos casos constitucionales no se pueden decidir bien sin introducir una teoría más ambiciosa. Si hay una buena teoría disponible (que incluya, por ejemplo, el derecho a la libertad de palabra) y si se puede persuadir a los jueces de que la teoría es buena, su aceptación judicial no debería ser tabú.

¿Y qué pasa con el desacuerdo? Hasta ahora la discusión se ha enfocado en la necesidad de convergencia. Tal necesidad existe de verdad; pero no es la única parte del cuadro. En derecho, como en política, el desacuerdo puede ser una fuerza productiva y creativa que revela los errores, muestra brechas, moviliza la discusión y los resultados en buenas direcciones. El orden constitucional estadounidense ha dado gran valor al "gobierno por discusión", y cuando el proceso está funcionando bien, esto es cierto para la rama judicial y también para otras instituciones. Los acuerdos pueden ser el resultado de la coerción, sutil o no, o de un fracaso de la imaginación. 
Los desacuerdos constitucionales tienen muchas fuentes legítimas. Dos de estas fuentes son de importancia especial. Primero, las personas pueden compartir compromisos generales y no estar de acuerdo en decisiones particulares. Segundo, los desacuerdos de las personas sobre principios generales pueden producir desacuerdos sobre decisiones particulares y también sobre proposiciones de bajo nivel. Las personas que piensan que un principio de autonomía da razón de la libertad de expresión, pueden también pensar que el gobierno no puede regular la veracidad de las propagandas comerciales, -mientras que quienes piensan que la libertad de expresión es básicamente una idea democrática, centrada en la expresión política, pueden no estar interesados para nada en proteger la propaganda comercial. La teoría académica puede tener una función saludable en parte porque pone a prueba los principios de bajo nivel confrontándolos con exigencias más ambiciosas. Los desacuerdos pueden ser productivos en virtud de este proceso de examen.

Ciertamente nada malo ocurre si toda persona con una concepción general razonable coincide con un juicio particular (razonable por hipótesis). Pero si un acuerdo carece de teoría completa, existe el riesgo de que se equivoquen todos los participantes en el acuerdo y que por lo tanto la decisión sea equivocada. También existe el riesgo de que alguien razonable no haya participado, y que si se lo incluyera se desmoronara el acuerdo. Con el tiempo, los acuerdos de teoría incompleta deberían estar sujetos al escrutinio y a la crítica. Ese proceso puede desembocar en un pensamiento más ambicioso del que habitualmente está implicado en el derecho constitucional.

Tampoco el consenso social es una consideración de mayor importancia que las demás. Por lo común es mucho mejor tener una solución justa, rechazada por muchos, que una decisión injusta en la que están de acuerdo todos o la mayoría. Una Constitución justa es más importante que un acuerdo sobre la Constitución. El consenso o acuerdo es importante más que todo por su conexión con la estabilidad, la que es en sí misma una meta valiosa pero no la más importante. Como escribió Thomas Jefferson, un grado de turbulencia es productivo en una democracia. ${ }^{15}$ Bien podría ser correcto hacer que un orden constitucional injusto fuese mucho menos estable. Hemos visto que acuerdos carentes de una teoría completa que los respalde, aunque sean estables y con amplio apoyo, pueden esconder o reflejar injusticia. Ciertamente, los acuerdos

${ }^{15}$ Por lo que Jefferson decía que la turbulencia es "productiva del bien. Previene la degeneración del gobierno, y nutre la atención general hacia los asuntos públicos. Sostengo que un poco de rebeldía de vez en cuando es una buena cosa". Carta a Madison (enero. 30, 1798), reimpresa en: Peterson, Merrill D., (ed.) The Portable Thomas Jefferson. Viking Press, New York, 1975. 
deberían tener una teoría más completa cuando la teoría pertinente es obviamente correcta y cuando esto se le puede demostrar a la gente, o cuando se hace necesario invocar la teoría para decidir algunos casos. Nada de esto es inconsistente con lo que he afirmado aquí.

Sería una tontería decir que ninguna teoría general sobre el derecho constitucional o los derechos puede conducir a acuerdos, y aún mayor tontería sería negar que algunas teorías generales merecen apoyo, y la más grande de las tonterías sería decir que los acuerdos que carecen de teoría completa merecen respeto, cualquiera sea su contenido. Lo que parece plausible es algo no menos importante por su modestia: excepto en situaciones inusuales, y por múltiples razones, son las teorías generales un fundamento improbable para la construcción de Constituciones y para el derecho constitucional; y para los falibles seres humanos son apropiadas la precaución y la humildad sobre afirmaciones teóricas, al menos cuando múltiples teorías pueden conducir hacia la misma dirección. Este conjunto más modesto de afirmaciones nos ayuda a caracterizar los acuerdos carentes de teoría completa como importantes fenómenos con sus propias virtudes especiales. Tales acuerdos ayudan a hacer posibles las Constituciones y el derecho constitucional, aun en naciones cuyos ciudadanos no se ponen de acuerdo sobre muchos de los asuntos más fundamentales. De esta manera, los acuerdos de teoría incompleta nos ayudan a iluminar un perdurable rompecabezas constitucional y, por tanto, social: cómo miembros de diversas sociedades pueden trabajar juntos en términos de respeto mutuo en medio de agudos desacuerdos sobre lo correcto y lo bueno. Si existe una solución a este complicado rompecabezas, los acuerdos carentes de teoría completa son un buen punto de partida. 
